\title{
A prática da pesquisa em Comunicação: abordagem metodológica como tomada de decisões
}

\author{
José Luiz Braga
}

\section{Resumo}

0 texto toma como eixo a questão prática de como fornecer, na realidade atual dos programas de pós-graduação em Comunicação, apoio para 0 encaminhamento metodológico adequado de teses e dissertações. Assume que pesquisas empíricas são um processo formativo essencial para mestrandos e doutorandos. Considerando a ineficácia da adoção de regras metodológicas apriorísticas e rígidas e a grande variedade de ângulos teóricos e de tipos de objeto na área, propõe perspectivas básicas e transversais para cuidados metodológicos, adequados à diversidade de pesquisas qualitativas. Observa que 0 abandono das regras apriorísticas torna a tomada refletida de decisões um elemento central do encaminhamento metodológico. 0 artigo oferece reflexões sobre três elementos da pesquisa: problematização, fundamentação teórica e observação empírica. Trata finalmente das objeções como processo central no avanço do conhecimento.

\section{Palavras-chave}

Pesquisa em Comunicação. Metodologias. Currículo. Fundamentação teórica. Observação Sistemática. Objeções.

\section{José Luiz Braga I jbraga@unisinos.br}

Doutor em Comunicação pelo Institut Français de Presse (IFP). Professor Titular no Programa de Pós-Graduação em Comunicação da Universidade do Vale do Rio dos Sinos (Unisinos).

\section{Preliminares}

Este estudo foi inicialmente escrito como base para participação em mesa redonda, no $\mathrm{V}$ Seminário Interprogramas da Compós ${ }^{1}$. A tônica do Seminário, mais que buscar uma acuidade conceitual abstrata sobre os temas previstos, voltava-se para alguns desafios concretos que podem afligir o desempenho formador dos cursos de mestrado e doutorado no país. As outras duas mesas de debates trataram da seleção de estudantes e das atividades de orientação.

Para nosso tema - metodologias de pesquisa - é menos evidente, em si, a notação prática, pois comporta certamente uma apropriação conceitual e abstrata. Mas, considerando que os contextos devem sempre ser significativos, assumimos que 0 tema desdobra-se na seguinte pergunta: como fornecer, na realidade atual de nossos programas de pós-graduação em Comunicação, apoio aos estudantes para o bom desempenho de suas investigações, de modo a que suas teses e dissertações alcancem resultados relevantes, com encaminhamentos metodológicos adequados? 
E, particularmente: de modo a que essa obra seja o principal indicador da boa formação do pesquisador que a produziu.

Essas questões dirigem seu desafio a todo o conjunto de atividades formativas em um programa de mestrado ou doutorado - todas as previsões curriculares recebem a incidência da questão. Uma parte das respostas relaciona-se às tarefas da orientação; outra parte, a disciplinas oferecidas em curso - sejam abrangentemente voltadas para metodologia e pesquisa, sejam especificadas por algum ângulo teórico, temático ou de encaminhamento. As demais previsões curriculares (seminários, publicação de textos, reuniões de grupos de estudo e pesquisa) recebem também a incidência da questão metodológica.

Nessa perspectiva, a questão das metodologias de investigação desdobra-se na questão dos procedimentos pertinentes para oferecer apoio - 0 que é um problema de metodologia pedagógica. Uma formação metodológica, em mestrado ou doutorado, não pode se restringir a informações sobre teorias e métodos. Deve-se fazer os estudantes refletirem sobre 0 enfrentamento da pesquisa, estimulando o desenvolvimento de abordagens metodológicas como práticas sobre seus próprios problemas de investigação.

Um dos objetivos centrais do trabalho de produção da tese ou dissertação, mais que os resultados de conhecimento produzidos sobre seus objetos, é a própria formação do pesquisador. Nessa formação, o desenvolvimento de competências metodológicas e de formulação teórica é o núcleo organizador.

Sabemos que toda discussão teórica, epistemológica e metodológica é importante para a formação de uma "cultura de pesquisa"; e que a obtenção de um bom manejo de perspectivas, conceitos e abordagens diversificados nesse âmbito é parte importante do programa pessoal de formação continuada de todo pesquisador. Mas aqui se trata de outra coisa, mais próxima, mais urgente e mais concreta - que é a oportunidade de usar a própria pesquisa de dissertação ou de tese como campo de prática, de formação de experiência sobre modos de encaminhar a pesquisa e para aprender com seus desafios.

Três preliminares devem ser levadas em conta, neste ponto. A primeira, de ordem teórico-metodológica, e pertinente à história do conhecimento nas Ciências Humanas e Sociais (CHS), é o forte consenso atual de que não é possível assumir abstratamente abordagens prévias e "fechadas", a serem aplicadas a uma diversidade de pesquisas. Assim, diferentes pesquisas solicitam diferentes aproximações, conforme suas perguntas e objetos; e mesmo táticas metodológicas comprovadas e pertinentes devem ser ajustadas a características concretas do objeto e ao desenho específico da investigação. Mas isso não deve ser pretexto para "vale tudo". Ao contrário, as exigências se ampliam. 
Não sendo o campo da Comunicação dotado de um sistema positivista de objeto/método nem de uma sedimentação consensual de referências teórico-metodológicas enraizadas na tradição, corre-se 0 risco frequente de improvisação, de impressionismo, de espontaneísmo, de reduzido rigor, de utilização de senso comum simplificador. Torna-se assim relevante referir, a cada pesquisa, as bases teóricas e técnicas gerais de aproximação do objeto da pesquisa, não pela aplicabilidade imediatista, mas em favor de uma percepção razoável do que seja o trabalho de "fazer ciência" (com todas as ressalvas que se queira fazer quanto a este conceito). No espaço de um mestrado, não fazemos jornalismo, literatura, arte, militância. Temos o objetivo de produzir conhecimento, embora esse fazer científico, hoje, no espaço das ciências humanas, não se pretenda puro, nem objetivo, nem neutro. Ainda que seja possível e desejável desenvolver interações instigantes com os fazeres acima referidos, 0 que especifica nosso trabalho é a produção de conhecimento acadêmico.

A segunda preliminar, de ordem históricocontextual, referida especialmente à pesquisa no Campo da Comunicação, é a extraordinária diversidade de temas, objetos, questões, ângulos, conceitos, paradigmas e teorias que hoje são acionados, conforme as escolas, as áreas de interesse e as linhas de pesquisa. A solicitação de transferência do que seja aprendido, de uma questão para outra, é mais ampla, talvez, do que em outras disciplinas humanas e sociais.
Como sabemos, a aprendizagem efetivamente se transfere de um objeto para outro. Se aprendi a usar bem a abordagem " $x$ " em uma pesquisa, amanhã saberei usar essa experiência para me apropriar mais facilmente da abordagem " $y$ " solicitada por outra pesquisa. Mas no espaço em que inscrevo a presente reflexão, estamos interessados em algum tipo de apoio mais imediato, voltado diretamente para a pesquisa que 0 estudante tem diante de si.

0 que oferecer com eficácia, nestas condições? Não apenas que possa ser adequado ao que cada estudante pretende pesquisar, mas também que esteja minimamente dentro de nossas competências de docentes que, evidentemente, não podem abranger a formidável diversidade do que é teórica e metodologicamente disponível.

Diante de tal questão, uma terceira preliminar deve ser a de evitar meramente inculcar em nossos estudantes as nossas próprias preferências teórico-metodológicas - 0 que corresponderia a ficar indiferente às necessidades específicas, certamente diferenciadas, de um grande número de mestrandos e doutorandos. Certamente as preferências teórico-metodológicas do professor - e sobretudo da linha de pesquisa - têm um papel a cumprir. A terceira preliminar assinalada apenas alerta que tais preferências não devem "se abater" sobre os estudantes, nem de modo autoritário nem em desconsideração de necessidades específicas de sua pesquisa. 
No conjunto de um programa e de uma linha, qualquer encaminhamento deve ser justificado por sua pertinência.

É claro que disciplinas específicas, voltadas para um ângulo teórico-metodológico determinado e oferecidas com essa visada, devem mesmo encaminhar, com rigor e profundidade, suas perspectivas e processos próprios. Como serão disciplinas optativas, vão cursá-las, esperançosamente, os estudantes que se percebam interessados, considerando essa formação específica relevante para seus objetivos de investigação.

As três preliminares apontadas correspondem a outros tantos desafios para o trabalho dos professores e dos estudantes nos PPGs.

Malgrado a superação de abordagens fechadas $a$ priori, apesar da diversidade de objetos e teorias e das preferências teórico-metodológicas variadas, queremos abordar aqui a questão das necessidades gerais, abrangentes e transversais de uma formação metodológica básica. 0 que se deve prever, nessa perspectiva, que corresponda a algo de produtivo para toda uma diversidade de pesquisas?

Deve-se tratar naturalmente de aproximações tão básicas que possam ser ajustadas a temas e teorias bem diversos. Percebo que, às vezes, aproximações muito sofisticadas e pertinentes aos objetos de pesquisa dos estudantes deixam de render seus melhores resultados de investigação - justamente na falta de decisões e procedimentos bem mais elementares que, se assegurados, poderiam dar sustentação adequada àqueles encaminhamentos. Como toda investigação comporta riscos, é preciso estar liminarmente atento a sua ocorrência, sem o que não se estará preparado para buscar correções ou defesas.

0 que desenvolvo, no presente texto, não é resultado de uma aproximação abstrata - decorre de alguma experiência no enfrentamento prático desse desafio. Por isso mesmo, as proposições que faço não se pretendem universais, a ponto de serem aplicáveis a qualquer situação formadora, em apoio a qualquer tipo de pesquisa comunicacional. Mas estou convencido de que, trabalhadas reflexivamente por colegas, em função dos desafios pedagógicos e metodológicos em sua orientação e seu ensino, poderão estimular táticas - por transferência, reajuste ou substituição pertinentes para seu trabalho docente.

Essas pretensões distinguem-se, entretanto, de uma "tática de manual de pesquisa". Na perspectiva de manual, os autores oferecem informações básicas para uma espécie de "desenho médio" de uma pesquisa padrão. Minha preocupação, bem diferente, é a de oferecer ângulos a serem refletidos e cuidados pelos professores e pelos pesquisadores-estudantes como pistas para seus próprios encaminhamentos, diferenciados em função de seu objeto e de seus fundamentos teóricos. 
Reiterando essa visada prática e um objetivo de tratar questões muito básicas, com alguma possibilidade de valor transversal a diferentes âmbitos teórico-metodológicos, organizei 0 presente texto em torno dos seguintes subtemas:

- a importância da pesquisa empírica e a necessidade de critérios "internos" de rigor;

- uma reflexão sobre o próprio sentido de "metodologias" nas circunstâncias referidas;

- os três principais elementos a serem articulados em uma pesquisa: problematização e hipóteses; fundamentação e tensionamento; 0 trabalho de observação;

- espaços mais habituais de risco em uma pesquisa de pós-graduação;

- 0 trabalho de objeção como componente metodológico.

\section{A importância da pesquisa empírica}

Defendo para nossa pós-graduação - e particularmente para os mestrados - a importância da realização de uma pesquisa empírica, a pesquisa que solicita uma efetiva observação de algum ângulo da realidade, apresentando perguntas sobre aspectos de uma determinada situação ou "objeto" e procurando respostas diretamente através de investigação sistematizada de elementos concretos que compõem o objeto escolhido e construído.
É bom enfatizar que não é "pesquisa empírica" apenas aquela investigação explicativa, realizada com controle rigoroso de variáveis e/ ou desenvolvida por aproximação quantitativa. 0 trabalho de compreensão do objeto empírico, a reflexão sobre "situações indeterminadas" (nãoesclarecidas) do ambiente social, na pesquisa qualitativa, corresponde igualmente a pesquisa empírica - bastando que a motivação principal do pesquisador se volte para efetiva descoberta de conhecimento sobre tais materiais, orientado por teorias pertinentes.

Isso não significa que "pesquisas teóricas" sejam irrelevantes, no quadro abrangente de produção da pesquisa em uma área de conhecimento. Mas apenas que os mestrados - e muitas vezes também os doutorados - não são o melhor momento para tal exercício exclusivo. Ao contrário, processos exclusivamente centrados no estudo de autores, para gerar dedutivamente ainda outras ideias, parecem solicitar uma experiência bem mais aprofundada do que nossos mestrandos e doutorandos tipicamente possuem. Além disso, solicitam um tempo maior do que se dispõe na situação de formação.

Um argumento adicional - e talvez mais importante - é que o mestrado e o doutorado podem ser a única oportunidade apoiada que um pesquisador em formação terá para se defrontar com os desafios práticos e com as dificuldades metodológicas de organizar um trabalho de investigação que os ponha efetivamente a braços 
com uma realidade que resiste, que apresenta fatos incontornáveis, que não se resolve apenas com base em argumentação e especulação abstratas. Em última análise, queremos "falar sobre o mundo" - mesmo quando se faz a filosofia mais abstrata e sofisticada. Se o estudante tiver a pretensão de entrar diretamente nesse mundo rarefeito da especulação, que contato terá tido com a resistência das coisas?

Outro ângulo é o da importância da descoberta como elemento relevante - tanto da contribuição para o conhecimento como do estímulo para 0 árduo trabalho da pesquisa. Falo aqui das descobertas efetivas sobre características intrigantes do mundo real. 0 trabalho de elaborar formulações teóricas sobre tais descobertas é uma experiência necessária para 0 bom pesquisador. Se todo o trabalho de pesquisa corresponder apenas a elaborações dedutivas e ensaísticas - mesmo sofisticadas - a partir do que outros autores escreveram, faltará esse aspecto fundamental à experiência de nossos mestrandos e doutorandos.

Não é preciso que as descobertas realizadas nas pesquisas empíricas se caracterizem como a vanguarda do conhecimento na área - nossas descobertas raramente 0 são. Trata-se mesmo de enfrentar a resistência da realidade, cercála com nossa problematização e ser capaz de perceber alguma coisa ali que, por mais modesta e singular, antes não era claramente percebida, agora encontra um esclarecimento produzido por nosso trabalho investigativo, de observação sistemática, de questionamentos, de articulação adequada entre os fundamentos teóricos acionados e as dúvidas postas pela construção do objeto. Fala-se às vezes em "originalidade" (sobretudo para a tese de Doutorado). Mas esta é relativamente rara e depende de condições muitas vezes externas ao esforço investigativo. Mais importante é um esforço sistemático para a descoberta - 0 que é outra coisa.

Note-se que defender a pesquisa empírica não corresponde a uma visão empiricista desta que leve a proposições meramente descritivas, limitando a investigação a uma factualidade superficial ou "mecanicista". Ao contrário. Não se trata de eliminar ângulos interpretativos, de descartar insights ou de fugir da construção conceitual ou da fundamentação que orienta 0 olhar sobre o objeto. Uma boa pesquisa elabora estas e outras démarches mais abstratas, alimentadas pelo conhecimento teórico. Apenas, aciona estes elementos menos materiais submetendo-os ao crivo do enfrentamento das coisas. Não podem ser desenvolvidos e elaborados apenas com base em uma sabedoria verbal, argumentativa, especulativa e abstrata.

0 trabalho metodológico corresponde, na pesquisa empírica, a pôr tais elementos abstratos a serviço de um problema-eixo, voltado para efetivas descobertas. Essa experiência só ocorrerá através do desenvolvimento de pesquisas empíricas no mestrado e no doutorado.

A pesquisa empírica, que não elimina - ao contrário, solicita - a boa reflexão teórica, 
proporciona, durante o próprio trabalho, a possibilidade do exame refletido de seu rigor - justamente pelo tensionamento mútuo e pelas articulações que se possam fazer entre três elementos bem diferenciados que se apoiam e se cobram mutuamente: a construção e problematização do objeto; 0 trabalho de fundamentação teórica; e a ida à realidade para sua observação sistemática.

0 manejo reflexivo desses três elementos, na busca de uma construção harmônica, deve ser uma experiência fundamental para o futuro pesquisador - sobretudo se este, mais adiante, pretende se aprofundar em formulações teórico-especulativas.

A prática da pesquisa empírica seria 0 único modo de gerar uma disciplina do pensamento, do conhecimento e do rigor reflexivo. A reflexão puramente ensaística, "a partir de autores", pede reflexões e debates de longo prazo, uma séria experiência dos estudos e do mundo, por parte do pesquisador, e debates em círculos de reflexão diversificados e em continuidade. Estamos falando da formação de pesquisadores - nesse nível, se determinadas experiências não forem oferecidas, provavelmente não haverá outras oportunidades.

Assumindo a importância da previsão de posturas transversais básicas para a diversidade de aproximações possíveis e a ênfase a ser dada ao trabalho de formação, sublinho a seguir, na discussão sobre "metodologias", os aspectos que as caracterizam como uma lógica das tomadas de decisão na preparação e no desenvolvimento da pesquisa.

\section{3 "Metodologias"}

A relevância das questões metodológicas na pesquisa é inconteste. Entretanto, ocorre às vezes uma espécie de reconhecimento automático que se exprime apenas no nível das considerações teóricas e abrangentes, sem produzir consequências sobre a prática da pesquisa. Ou então, a prática é bem planejada, no nível das técnicas de observação, que são também instâncias metodológicas, sem preocupação com os encaminhamentos da reflexão teórica.

Às vezes parece haver a crença de que a presença de um "capítulo metodológico", na tese ou dissertação, corresponderia a uma exigência formal, dando conta da questão seja pela exposição das perspectivas teóricas habituais na área de interesse, seja descrevendo as práticas adotadas para observar 0 objeto.

Diferente de uma perspectiva sobre metodologia como um conjunto de regras de encaminhamento apriorísticas; ou como mero relato posterior de componentes adjetivos à substância do tema; ou ainda como simples adesão a um quadro teórico estabelecido; eu gostaria de enfatizar tais questões como ações concretas e refletidas durante todo 0 desenvolvimento da pesquisa, desde as primeiras hipóteses até os resultados finais.

0 abandono consensual de "metodologia" como aparato rígido, como "máquina formal" 
para processar neutramente a investigação, poderia levar o estudante à perspectiva de que a aproximação do objeto pode ser menos rigorosa. Ao contrário - 0 abandono da injunção determinante do "a fazer" impõe maior atenção e cuidados quanto ao "em fazendo". Nessa perspectiva, a metodologia é uma sabedoria na tomada de decisões em que o pesquisador se vê constantemente envolvido.

No campo de estudos em Comunicação, tais cuidados são particularmente relevantes, uma vez que importamos teorias, conceitos e metodologias de múltiplos horizontes - que pedem transferências e harmonizações complexas para funcionarem juntos.

$$
* * *
$$

0 mestrando e 0 doutorando devem ser estimulados a perceber que a noção de "metodologia" se relaciona a toda uma diversidade de ações de encaminhamento, assim como a uma variedade de instâncias de reflexão; e que as tomadas de decisão, passo a passo, implicam a necessidade de fazer distinções entre níveis e dentro de cada nível de elaboração.

No nível mais abrangente, encontramos questões de método na escolha de paradigmas e modelos epistemológicos. Vamos fazer uma pesquisa nomotética, em busca de regularidades no âmbito em estudo? Ou vamos fazer uma busca indiciária? 0 objeto é suscetível de abordagem histórica, solicitando a apreensão de estruturas complexas e singulares, que não serão "explicadas" em termos de causa e efeito, mas sim "compreendidas" em seu devir? Incluímos na busca de descobertas também uma angulação praxiológica? A visada será positivista ou fenomenológica?

As decisões tomadas sobre questões deste tipo devem ser coerentes com as visadas mais específicas da pesquisa e, ao mesmo tempo, repercutem direcionamentos sobre todos os outros processos da investigação.

Este é apenas o nível mais geral e abrangente das questões metodológicas. Encontramos em seguida as questões de fundamentação teórico-metodológica. As teorias que adotamos, normalmente, não apenas envolvem explicações da realidade, mas também fornecem os objetostipo que em seu âmbito são constituídos e alguma ordem de questões que lhes são dirigidas. Costumo me referir a estas como "questões de horizonte", pois ao trabalhar com uma teoria assumimos como horizonte de reflexão a ordem de questionamento diante da qual construímos nossas perguntas específicas de investigação.

Aparece, portanto, já aí, um conjunto de questões metodológicas, correspondente à escolha das teorias adequadas. $\mathrm{Ou}$, alternativamente, diante de uma escolha já feita de autores (por serem os de nossa preferência), devemos fazer opções pertinentes para a construção do objeto de pesquisa. Junto com isso, naturalmente, vêm os conceitos a adotar e desenvolver, as premissas e, eventualmente, um âmbito de produção de hipóteses. 
Na própria construção do problema - perguntas específicas, objetivos, construção do objeto - nos vemos a braços com decisões metodológicas referentes ao ângulo, à acuidade, à própria geração de perguntas. Construir um problema de pesquisa, em sua organização interna e suas vinculações com as bases teóricas e com uma realidade observável, envolve decisões metodológicas.

Em seguida, os problemas metodológicos se põem também para a escolha dos observáveis, para a construção de coerência entre estes e os objetivos da pesquisa, o que envolve decisões tanto sobre o tipo de materiais e situações; como sobre 0 conjunto específico e concreto a ser observado ("recorte", corpus, amostra, grupo, documentos, situações, pessoas etc.).

E aí aparecem as questões de abordagem metáfora que expressa bem a necessidade de enfrentamento muito concreto de realidades ora esquivas ora "impenetráveis". Manifesta-se a necessidade de decisões referentes ao "olhar", aos critérios de seleção, às ponderações entre diferentes indícios ou dados, às articulações entre componentes dispersos, aos procedimentos de interpretação, ao escopo e extensão das inferências. Depois das seleções e organização de dados e indícios, temos ainda decisões interpretativas; e finalmente, o retorno dos resultados ao âmbito da reflexão teórica, o que pede ainda novas decisões.

Embora apresentadas em uma espécie de sequência, acima, na verdade não há um ponto de partida definido para as tomadas de decisão na pesquisa - elas começam em qualquer ponto e se desenvolvem em todas as direções. Retornam em reiteração, de cada nível para todos os outros. 0 que importa, nesse espaço, é perceber que em todos os níveis e a cada passo da pesquisa, o pesquisador é solicitado a tomar decisões, teórico-epistemológicas ou práticas - e geralmente envolvendo articulações entre estas duas ordens.

A exigência de reflexão metodológica sobre todos esses elementos corresponde ao que considero um conceito geral de "metodologia". Longe de ser um receituário de passos a serem dados, trata-se do processo de encaminhamento de decisões parte sendo conhecimento estabelecido, a que devemos recorrer com pertinência; parte, prática incorporada, a ser desenvolvida durante toda a carreira do pesquisador; e parte invenção, a ser testada por sua coerência e seus resultados, no próprio exercício da pesquisa.

Não existindo receituário rigoroso e sintético, que possa ser usado como um check-list dos pontos a serem cuidados, as dificuldades podem parecer insuperáveis. Entretanto, se levarmos em conta aquela perspectiva de metodologia como 0 acompanhamento refletido daquilo que se está fazendo, podemos encontrar no próprio desenvolvimento da pesquisa as pistas para seu controle metodológico.

Costumo dizer a meus estudantes que a essência da reflexão metodológica se encontra na competência humana de, ao fazer qualquer coisa, termos a 
capacidade de observar e rever criticamente 0 que fazemos. Esse tipo de atenção nos oferece, então, a possibilidade de redirecionar, de reajustar, de corrigir. 0 processo metodológico básico não é o de definir uma regra de encaminhamento e depois segui-la estritamente; mas sim o de rever cada passo dado e refletir sobre a justeza de seu direcionamento, corrigindo-o no próprio andamento da pesquisa. Planejar é replanejar.

Como normalmente tomamos uma decisão porque estamos convencidos de sua justeza, é preciso dispor de alguns elementos de contraposição para testar sua efetiva adequação. Ora, uma pesquisa em andamento oferece toda uma variedade de testes e critérios. A cada decisão tomada, a cada encaminhamento previsto, podemos sempre observar sua incidência sobre os demais pontos da construção em processo. Como a escolha do problema repercute sobre a seleção dos observáveis? Como o modo de observar tensiona o modelo epistemológico preferido? Como as teorias adotadas pré-conformam o objeto? Como a observação prevista pede redirecionamentos do problema? E assim sucessivamente.

Como uma pesquisa é sempre um percurso iterativo entre suas partes, podemos "voltar atrás" e rever as decisões anteriores. No momento da observação podemos perceber que as perguntas da pesquisa ainda não tinham desprendido todo seu potencial de descoberta - e uma revisão dessas perguntas pode permitir um desenvolvimento qualitativo da investigação.
A rigor, não precisamos de "regras" e critérios metodológicos muito definidos para cada decisão a tomar - e dificilmente os teríamos à disposição. Isso não significa que se tomem decisões exclusivamente na singularidade da pesquisa, desconhecendo a experiência teórico-metodológica anterior. Conhecer essa experiência, geralmente via disciplinas e estudos metodológicos, deve justamente permitir 0 acionamento de decisões escoladas.

Agindo dentro de um corpo reflexivo geral, teórico-metodológico, dispomos então de uma espécie de padrão geral sobre "coisas a fazer e a não fazer". Podemos complementá-lo - e tensioná-lo produtivamente - pelo esforço de manter articulações dinâmicas entre os diferentes componentes de nossa pesquisa. $\mathrm{E}$ isso pode ser feito simplesmente relendo com frequência os textos parciais já escritos, refletindo criticamente sobre os passos já dados e revendo em continuidade nossas decisões, controlando cada uma das partes da pesquisa por sua articulação com as demais.

É isso que caracterizo como uma aproximação metodológica do "em fazendo", por contraste com uma previsão rígida e prévia do caminho "a fazer". É claro que estar atento aos componentes básicos de uma pesquisa - que são atravessados continuamente por aqueles níveis de tomada de decisão - ajuda o pesquisador mestrando ou doutorando a desenvolver acuidade para a revisão crítica daquilo que desenvolve. 


\section{Perguntas, objetivos, hipóteses - o problema da pesquisa}

Construir e problematizar um objeto de pesquisa não é apenas escolher um tema, um "recorte da realidade", e fazer-lhe algumas perguntas genéricas, buscadas no âmbito teórico. Bem mais que isso, envolve todo um enfrentamento, no qual as escolhas feitas, a própria percepção inicial sobre as coisas, são já elementos do processo construtivo - que, em certo sentido, pede "invenção". Mas essa invenção tem que sobreviver aos rigores da formulação conceitual e do enfrentamento da realidade.

Se construímos um bom problema de pesquisa, as demais atividades da pesquisa articulam-se com facilidade em torno. Mas isso não significa que se possa construir logo de início, de modo completo, um problema e que este, uma vez "pronto", passe a comandar estaticamente 0 processo. A construção do problema solicita de tal modo incursões nos outros dois elementos processuais da pesquisa, que deve ser frequentemente revista em função destes. É sob esta condição que o problema se caracteriza como verdadeiro eixo da investigação. ${ }^{2}$

Nessa concepção dinâmica, o "problema da pesquisa" não se esgota na "pergunta de partida". Envolve ainda os objetivos, as justificativas da abordagem proposta, suas articulações com 0 trabalho de observar e seus tensionamentos com a teoria. Assim, o problema da pesquisa não se apresenta apenas como uma relação entre a curiosidade do pesquisador ${ }^{3}$ e 0 objeto empírico percebido. As perguntas específicas da pesquisa, diretamente voltadas para a realidade, devem igualmente se articular com as "questões de horizonte teórico" relacionadas à fundamentação, para concretizá-las e/ou para tensioná-las. A elaboração de perguntas pede também um enfrentamento exploratório prévio dos materiais para preparar a "construção" - seleções, decisões sobre o que deve ser "objeto" e o que deve ser "contexto", sobre os ângulos mais promissores para sua aproximação.

A explicitação dos objetivos da pesquisa complementa as perguntas e a formulação do problema. É claro que o estudante e o orientador devem cuidar da estrita articulação entre 0 problema e os objetivos - estes repercutem aquele na forma seguinte: dadas tais questões, estes são os objetivos a que a pesquisa se propõe. 0 inverso seria válido, também: se estes são os meus objetivos, o que devo perguntar ao objeto?

Não é raro encontrar uma disjunção entre os dois componentes - 0 que evidencia uma reflexão insuficiente sobre a organização da pesquisa. Bem compreendidos em sua articulação, os objetivos compõem, com o problema, o eixo da investigação.

A metáfora do "eixo" me parece mais produtiva que a do "recorte". Essa última parece isolar o objeto, enquanto que o eixo justifica todas as relações necessárias, inclusive contextuais, de materiais e de conceitos que, percebidos relevantes, podem ser postos em rotação em torno e a serviço do problema 
0s objetivos são frequentemente organizados em dois patamares - gerais e específicos talvez mais pelo hábito que por necessidade. 0 fundamental para a pesquisa são os objetivos efetivamente especificados. 0s objetivos gerais corresponderiam às questões de horizonte teórico; e os específicos às perguntas voltadas para a realização concreta da investigação. Deve-se evitar, por isso mesmo, um excesso de objetivos. Quando estes aparecem em excesso, cria-se a impressão de que 0 pesquisador estaria tentando "atirar para todos os lados" na expectativa de captar alguma coisa meio por acaso. Além disso, um excesso de objetivos resultaria no atendimento apenas parcial da lista; ou em diluição resultante de um tratamento superficial de todos.

Quanto às justificativas, frequentemente encontramos, em projetos, em teses e dissertações, justificativas que enfatizam a relevância do tema ou a importância social de que tais e tais questões sejam pesquisadas.

Sem desprezar tal informação, as justificativas básicas de uma pesquisa devem corresponder à validade de seu problema específico e à boa fundamentação dos encaminhamentos propostos - e não ao interesse genérico de seu assunto. É nesse sentido que "justificativas" fazem parte da construção do problema.

No artigo Para começar um projeto de pesquisa, desenvolvi mais longamente a questão central da construção do problema, em termos de aproximação prática, sugerindo táticas para seu desenvolvimento. No presente texto não volto a fazê-lo, preferindo complementar a reflexão com algum desenvolvimento sobre a questão das hipóteses, enquanto parte relevante da elaboração do problema de pesquisa.

No artigo referido, junto com aquelas indicações práticas, desenvolvo a perspectiva de que em pesquisas qualitativas não precisamos, a rigor, de hipóteses - as perguntas e objetivos da pesquisa costumam fornecer o necessário e 0 suficiente para pôr em marcha uma investigação. Mantenho essa convicção. Mas o que percebo agora é que, se não precisamos de hipóteses, difícil é não tê-las; mais difícil ainda seria se livrar das que nos surgem tão logo começamos a prefigurar um projeto de pesquisa. As hipóteses nos surgem na forma de insights sobre o objeto, na forma de visadas teóricas já presentes no acervo de nosso conhecimento pessoal ou que aparecem nas leituras acionadas para desenvolver 0 projeto, ou ainda através das relações que vamos desenvolvendo entre a abstração teórica e a aspereza das coisas.

Nada contra essa "hipotetização espontânea". Nem seria possível investigar um segmento da realidade de modo "neutro e indiferente". Se não tivéssemos ideias a respeito das coisas, nem sequer pensaríamos em investigá-las. 0 próprio formato de nossas dúvidas já é um começo de hipotetização sobre como devemos construir a curiosidade.

A questão, assim, é sobre o que fazer com tais percepções preliminares. 0 primeiro passo, é claro, 
é 0 de organizar, selecionar, elaborar as "ideias" a respeito do objeto e das teorias acionadas. Uma parte desse esforço vai direcionar as descrições prévias que fazemos do objeto, as decisões sobre os contextos que assumiremos pertinentes, sobre as relações objeto/contexto a serem construídas, sobre os ângulos conceituais a serem enfatizados.

Uma parte dessas hipóteses prévias será dirigida à definição das premissas. Estas, como premissas, já não serão mais hipóteses, mas sim ponto de partida assumido, para todos os efeitos da pesquisa. Assim, não serão investigadas, pois foram adotadas (é claro que devemos ter boas razões para isso). Outras ainda, serão "hipóteses de trabalho" - proposições, ainda tentativas, que direcionam nossa investigação. São igualmente prévias e, embora possam ser modificadas em curso, não devem ser confundidas com "aspectos do problema": são antes processos metodológicos, de direcionamento para a busca de resposta.

Mas finalmente, algumas daquelas "ideias" iniciais sobre 0 objeto vão resistir e se caracterizar, propriamente, como "hipóteses de pesquisa" - ou seja, apresentam-se como "proposições em dúvida" e que deveriam ser esclarecidas através de investigação.

Como se articulam essas proposições com as perguntas de pesquisa? 0 que solicitam do trabalho de investigação propriamente dito que é a observação sistemática?
Em princípio, uma hipótese de pesquisa é uma pré-resposta às próprias perguntas da pesquisa. Pré-resposta porque ainda dubitativa; e possivelmente porque imprecisa ou incompleta. 0 que desejaríamos, intuitivamente, do trabalho de observação, seria checar se essa pré-resposta pode ser mesmo assumida como resposta.

Isso leva, às vezes equivocadamente, a se dizer que a pesquisa pretende verificar ou confirmar as hipóteses. Efetivamente, as pesquisas nomotéticas, que procuram leis e regularidades, querem isso mesmo: verificar. São em geral pesquisas quantitativas e/ou laboratoriais que, por isso mesmo podem ser chamadas de "verificacionistas". Estas pretendem confirmar ou infirmar uma proposição rigorosa e específica inicial. Não sabemos, entretanto, no início da pesquisa, se essa proposição efetivamente corresponde a "relações necessárias que decorrem da natureza das coisas". ${ }^{4}$ Tais hipóteses trabalham sobre poucas variáveis, controladas, e são apreensíveis em formulação binária, por exemplo - "fumar provoca câncer (sim ou não)". Quando o pesquisador não consegue, após tentativas controladas com esse fim, demonstrar a "hipótese zero", contrária a sua "hipótese do pesquisador", pode então considerar esta última "verificada" (em tais e tais condições).

Entretanto, as hipóteses-insight que dão base a pesquisa qualitativa dificilmente se comportam assim. As variáveis são em maior número, menos 
controladas, não suscetíveis de verificação tipo "sim/não": apreendem as coisas em perspectiva de compreensão mais que de explicação; e não expressam, tipicamente, regularidades rigorosas. Nessas condições, "confirmar" ou "infirmar" não é a meta para tais hipóteses.

Seria possível dizer (e os pesquisadores nessa situação efetivamente 0 dizem): "mas talvez a gente acabe provando que a hipótese não é verdadeira e, portanto, há realmente alguma coisa a investigar". Além de ser frustrante fazer uma pesquisa apenas para provar que estamos errados, essa prova dificilmente ocorrerá. Primeiro, porque, motivados pelo insight, trabalharemos tendencialmente para "provar" essa ideia - gerando uma cegueira involuntária para todos os dados que a contrariem. Segundo, porque provavelmente uma ideia gerada por forte envolvimento com a coisa é mesmo "verdadeira" (isto é - válida para o espaço e conjuntura em que foi proposta) - e se sustenta pela própria constatação "ao vivo", sem precisar de pesquisa para demonstrá-lo. 0 senso comum basta para sustentá-la.

0 que podemos pretender, então?

\section{A démarche básica corresponderia a assumir que} as percepções "de partida" são excessivamente simples ou relativamente equivocadas, em todo caso incompletas. 0 trabalho de pesquisa envolve (em perspectiva oposta à nomotética), desenvolver, tornar mais complexas, aprofundar, ajustar ou mesmo substituir radicalmente as hipóteses de partida por outras, mais adequadas ao conjunto de indícios disponíveis, sistematicamente levantados e articulados.

As hipóteses iniciais de apreensão geral do objeto - sua própria definição inicial, enquanto "questão em investigação" - provavelmente baseiam-se nos indícios inicialmente mais evidentes; e/ ou em premissas dependentes do conhecimento estabelecido (teorias) sobre a classe de fenômenos em que inscrevemos o caso. Assim, uma atitude metodológica consistente deve ser a de resistir à tentação de apenas confortar as hipóteses iniciais. Se os insights são válidos, em perspectiva de senso comum, não se trata de infirmar; mas é irrelevante apenas confirmar.

Isso significa que aquelas ideias prévias devem ser tensionadas pela reflexão teórica e pelo trabalho de investigação - não com a perspectiva de infirmar, mas de superar: de tornar as hipóteses mais complexas, mais abrangentes, mais finas, melhor formuladas; ou de encontrar outras hipóteses derivadas que substituirão as anteriores com vantagens. $\mathrm{Ou}$ ainda, de obter maior precisão sobre 0 âmbito de sua validade, em formulação rigorosa. Isso pede resistir a uma valoração universalizante de sua validade; e 0 desenho das condições em que a proposição é pertinente - com explicitação dos limites dessa pertinência e das cautelas no manejo da afirmação.

Simplesmente "confirmar uma hipótese de partida", em uma pesquisa qualitativa, corresponderia a um relativo fracasso, pois a rigor já pudemos chegar à proposição com base 
na experiência e na reflexão. A pesquisa teria sido, então, de pouca relevância. Apenas infirmar as hipóteses seria abandonar a investigação em meio de caminho - pois as razões que nos levam a desconsiderar as proposições iniciais devem abrir caminho para outras proposições em substituição. 0 que queremos, então, é que a pesquisa nos ofereça condições de produzir, com base na investigação, o aperfeiçoamento ou a superação das hipóteses iniciais: melhores hipóteses.

Tais "hipóteses finais" serão, entretanto, submetidas a dois níveis de "teste". Em um primeiro nível - pela observação de sua própria competência para efetivamente estabelecer relevância de indícios e para articular esses indícios em um "quadro perceptivo" do objeto. Podemos dizer que se trata de uma boa resposta se efetivamente articula os dados, confirmando sua relevância e apresentando coerência entre estes; e se faz interpretações evidentemente derivadas dos dados assim organizados.

Entretanto, as respostas devem passar por um segundo nível de teste: 0 enfrentamento da falseabilidade decorrente de objeções. Não se trata, aí, de propostas de desacordo a partir de tal ou tal teoria estabelecida - uma vez que 0 desacordo seria mútuo, entre o modelo singular e a teoria, restando em suspenso e dependente de avanços posteriores saber qual estaria mais próximo de uma visão rigorosa das coisas. A falseabilidade depende de se assinalar, no objeto, indícios contraditórios com o modelo; ou indicar incoerência da articulação hipotetizada. As objeções mais interessantes são aquelas que evidenciam a insuficiência da resposta proposta, discutindo a coerência da articulação ou a pertinência do que foi inferido.

Com essa perspectiva, compreende-se que nossas "ideias iniciais" a respeito do objeto em investigação fazem parte, diretamente, do trabalho de problematização. É fácil perceber os vínculos construtivos entre perguntas, objetivos, hipóteses e justificativas do encaminhamento.

\section{Fundamentação e tensionamento - os usos da teoria}

É importante considerar as relações entre os textos teóricos, a que se fará referência na pesquisa, e 0 trabalho propriamente de investigação (construção de problema, contextualizações, objetivos, observação etc.).

Para além dos processos de observação e levantamento de dados ou percepção de indícios, precisa-se, naturalmente, de fundamentos teóricos na base de uma pesquisa empírica. Uma visão empiricista que pretenda extrair conhecimento diretamente do material ou situação observada, a "olhos nus", não iria muito além de descrições superficiais, de senso comum ou em perspectivas idiossincráticas.

Por outro lado, chegar à pesquisa rigidamente aparelhado de teorias irremovíveis também não promete grandes avanços de conhecimento. A tendência, aí, seria a de "demonstrar" que a 
visão teórica pré-adotada é capaz de explicar totalmente 0 caso singular selecionado. Nesse caso, a pesquisa se limitaria a ilustrar a teoria com mais um caso. Nem se desenvolve a teoria, nem se amplia o conhecimento do objeto em sua especificidade - 0 resultado do estudo seria apenas uma descrição do objeto "nos termos da teoria tal" ou sua categorização em um sistema classificatório apriorístico.

0 trabalho de relacionar conceitos e teorias, de um lado, e questões concretas pertinentes a uma investigação, de outro, não se faz sem dificuldades. Adoto a noção de "tensionamento" como preferencial para esse trabalho.

Outras palavras são corriqueiras, nesse âmbito: "aplicar" (perspectivas, conceitos e teorias à pesquisa); desenvolver a "fundamentação teórica" ou teórico-metodológica da pesquisa. Certamente são válidas. Mas outros ângulos importantes do trabalho de articulação teoria/pesquisa não podem ser deixados na obscuridade, ou ser interpretados restritivamente.

Se entendêssemos em modo restrito a palavra "aplicar", arriscaríamos pensar o trabalho conceitual para a investigação como uma coisa meio mecânica, de adoção de teorias e conceitos diretivos, conformando o trabalho de investigação como uma técnica de "aplicação de regras e receitas". "Aplicar", portanto, deve ser visto em sentido mais sutil que o literal. Senão, estaríamos assumindo que os conceitos têm o poder de moldar a realidade - e só veremos o que já foi visto antes, pelos autores das teorias e conceitos adotados.

0 resultado, aqui, seria 0 de meramente usar a teoria para explicar, sem restos, o objeto específico de nossa pesquisa, assim como o faz em modo abrangente para a classe geral de objetos em que inscrevemos o nosso.

A ideia de "fundamentação teórica" é tradicional e rica - não deve ser abandonada. Devemos é evitar a impressão de que esses "fundamentos" podem sustentar sozinhos (só-teoria, só-abstração) o trabalho de enfrentamento da investigação no mundo empírico. A teoria é com certeza um dos fundamentos básicos da pesquisa - pois não pesquisamos a partir do zero e sim do conhecimento estabelecido pertinente. Mas se não misturarmos, na massa de que se farão os alicerces da pesquisa, as questões e a espessura própria da realidade empírica, eles não terão resistência e estrutura para sustentar o edifício ${ }^{5}$.

Sem esse cuidado, poderíamos estar apenas falando sobre o objeto no jargão teórico adotado ou usando características do objeto para "ilustrar a teoria". Como pesquisamos para descobrir coisas a respeito do objeto em investigação (problematizado, portanto), tais descobertas, mesmo singelas, por definição não existiam, antes, no corpo conceitual adotado. Devem ser feitas caber, depois, no corpo teórico 
em que inscrevemos nossa pesquisa. Esse esforço corresponde a um tensionamento entre objeto e teoria.

É preciso evitar, entretanto, uma interpretação restritiva para 0 trabalho de tensionamento. "Tensionar" não deve ser usado com o sentido de recusar, achar defeitos, fazer restrições - mas sim de trabalhar os componentes da articulação de modo a fazê-los relacionados em convergência. Salvo na hipótese de total ajuste harmônico entre as teorias adotadas e as démarches de uma pesquisa (o que seria raro ou artificial), trabalhar a articulação de conceitos e abordagem implica negociações entre 0 abstrato e a ação de investigação. Uma parte dessa negociação (e talvez redirecionamentos) se fará na prática da observação e da coleta de dados. Quanto mais conscientemente 0 pesquisador enfrente essas disjunções e expresse suas decisões a respeito, mais contribuirá para 0 conhecimento em sua área.

Outra parte do trabalho de articulação/ tensionamento deve, inevitavelmente, ser feita ainda nas fases preliminares - de problematização, de planejamento da pesquisa: com aquelas teorias que, mais de perto, oferecem estímulos à construção do problema, que fornecem premissas instigantes, em cujo âmbito se põem conceitos a serem usados para construir o objeto e sugerir indicadores ou tratamento. Tais conceitos podem ser "testados" pelas resistências encontradas na pesquisa, em sua especificidade.
Decorre daí que nem toda teoria, nem toda oferta bibliográfica se presta igualmente a esse exercício de articulação central.

De um lado, temos proposições teóricas de abrangência, que oferecem âmbitos gerais de "falas sobre o mundo", no contexto mais amplo da pesquisa, e que podem ser tomados como 0 espaço de nossas crenças básicas com relação ao conhecimento do tipo de objeto que nos interessa. Tais proposições abrangentes ("de horizonte") certamente não serão negociadas: são adotadas e idealmente - expressas com clareza nos relatórios de pesquisa. Entretanto, não se faz pesquisa para confortar doutrinas - por mais relevantes que nos pareçam. A teoria não pode, portanto, estacionar nesse nível de fundamentação.

Em âmbito teórico próximo a este, encontramos a teoria como conhecimento já constituído sobre aspectos de nosso objeto e seu contexto. Não precisamos "pesquisar tudo" a respeito do objeto de nosso interesse - 0 que obrigaria a refazer, no âmbito da pesquisa, todo o caminho do conhecimento sobre 0 objeto ${ }^{6}$ Deixaremos de problematizar diversos aspectos do objeto que, para os efeitos da pesquisa, serão considerados secundários em relação ao que questionamos. Para aqueles ângulos "complementares", usaremos normalmente 0 conhecimento estabelecido - uma parte do qual nos vem de revisões bibliográficas e da pesquisa recente sobre objetos similares. Por definição, não cabe problematizar nem tensionar tais proposições assumimos, simplesmente, que "informam" o objeto. 
Esses dois âmbitos de referência bibliográfica - 0 das teorias abrangentes, em cuja "fala sobre 0 mundo" nos inscrevemos; e o do conhecimento estabelecido e aceito sobre a classe de objetos fornecem, sem dúvida, textos importantes para nossas pesquisas. Para além desses dois aportes, porém, é que encontraremos as teorizações mais centralmente relevantes para a pesquisa específica: aquelas que tensionam o objeto e que devemos inversamente tensionar pela pesquisa, para extrair o melhor que podem nos oferecer.

Ao pesquisar um objeto, para além de sua inscrição possível em um âmbito teórico e/ou sua categorização, interna ou entre similares, com base em um sistema classificatório estabelecido (démarches certamente válidas, mas parciais), temos também a expectativa de encontrar "restos": ângulos ainda não plenamente esclarecidos, espaços não totalmente cobertos pelas teorias solicitadas. Esse tipo de esforço reflexivo é que pode ser caracterizado como de tensionamento mútuo entre teoria e objeto, potencializado pelo modo como problematizamos o caso.

Mais do que "aplicar" teorias e conceitos para apreender, categorizar ou "explicar" completamente um objeto ou situação empírica, trata-se de problematizar o objeto em estudo a partir dos fundamentos adotados. Se determinados conceitos, premissas, hipóteses heurísticas ${ }^{7}$ forem adotadas, que desafios e questões dirigem a esse objeto? Este é 0 tensionamento do objeto pela teoria.

Paralelamente, 0 objeto pode sempre desprender questões, desafiar a teoria nos âmbitos do concreto. Sendo abstração, e sendo provavelmente desenvolvida a partir de outras questões e materiais do mundo, é pouco provável que uma teoria possa dar conta integralmente de todos os aspectos que se desdobram de situações específicas outras. Aliás, se as teorias adotadas lograssem "explicar" completamente, isto é, à nossa satisfação, os objetos que nos interessam, não haveria razão para pesquisá-los. É assim que o objeto pode sempre, de algum modo, tensionar as teorias adotadas. Não no sentido de negá-las, mas de complementar com ângulos específicos; de observar diferenças na semelhança (realizações singulares ainda não percebidas na proposição geral), ultrapassando o nível "geral" da proposição abstrata e buscando perceber "variações internas" desta; ou de observar semelhanças para além das especificidades de cada variação. Tais tensionamentos permitem outras proposições gerais hipotéticas para apreensão do objeto - que não negam necessariamente a proposição geral de

Outra metáfora recorrente em pesquisa, a partir da própria etimologia da palavra "método" - caminho para uma meta a atingir. Que, aliás, é informada por sua experiência e por suas leituras.

As hipóteses heurísticas correspondem a inferências abdutivas elaboradas a partir de dados parciais disponíveis, e que são então assumidas - provisoriamente - como possíveis. Acionadas, para todos os efeitos de uma pesquisa, pode-se então perceber o retorno obtido da realidade observada quando o fazemos na ótica dessa hipótese. Note-se que não se trata de uma "hipótese de pesquisa", mas de um instrumento de questionamento e de observação para gerar descoberta. 
partida, mas que podem assinalar perspectivas mais interessantes para o exame de casos daquele tipo.

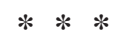

Encontramos, na discussão acima quatro níveis diferentes de uso possível de teoria em uma pesquisa.

\section{Teoria como visão de base (fundamentos)}

Teoria como proposições abstratas a respeito de determinados tipos de objeto, de questões de conhecimento: é o espaço de nossas crenças fundamentais sobre 0 conhecimento e suas possibilidades. Nesse nível, com relação à pesquisa, a teoria precede 0 objeto - funciona como "fundamento". 0 gesto de acionamento é 0 da adoção.

\section{Teoria como conhecimento estabelecido}

Para além dos fundamentos propriamente ditos, utilizamos teorias pelo que elas explicam sobre nosso objeto e seu contexto. 0 fato de dispor de tais conhecimentos já elaborados nos dispensa de um esforço excessivamente diversificado e abrangente de busca, permitindo a concentração do pesquisador nos aspectos propriamente problematizados de seu objeto. 0 gesto de acionamento teórico é o de selecionar as informações teóricas disponíveis e de organizá-las com pertinência, como suporte complementar para nos oferecer um objeto parcialmente conhecido, e/ou como conexão asseguradora de proposições ou descobertas desenvolvidas na investigação.

\section{Teoria como acionamento metodológico}

Percebemos dois ângulos principais de

acionamento metodológico:

- teoria como reflexões que ajudam a construir um problema de pesquisa - a selecionar pertinências, a perceber relações entre as coisas (e entre as coisas e os conceitos) e portanto a problematizar o objeto segundo essas relações;

- teoria como conjunto de conceitos que dá apoio ao trabalho de observar sistematicamente um objeto, de direcionar as perspectivas para interrogá-lo.

Nesse âmbito, não basta apenas "conhecer a teoria" - é preciso acioná-la a serviço de nossa pesquisa. 0 que podemos chamar de "construção de aparato metodológico" de uma pesquisa é esse trabalho sobre a teoria, fazendo-a dialogar com nosso objeto e nosso problema, para fornecer encaminhamentos à pesquisa.

Nesse aspecto, as teorias, certamente poucas e bem direcionadas, são efetivamente usadas e tensionadas pelo objeto. Elas não devem explicar sem restos - pois se assim fosse, a pesquisa seria desnecessária. Antes, fornecem instrumentos que nos permitem interrogar 0 objeto. 0 gesto de acionamento é o uso de teorias para perguntar, para planejar a observação sistematizada e para apoiar 0 trabalho de interpretação e inferências. 


\section{Teoria produzida pela pesquisa (objetivo básico da pesquisa)}

Trata-se da teoria como diálogo produzido entre os resultados de uma pesquisa específica e as teorias estabelecidas (desde ângulos complementares, até revisões fundamentais da teoria).

Temos aqui outro diálogo, de certo modo inverso aos anteriores. As perspectivas teóricas resultantes da pesquisa - os resultados do problema abordado na pesquisa - direcionam o olhar para novos conhecimentos e reflexões a respeito da realidade considerada. $0 \mathrm{~s}$ conhecimentos obtidos estão, é claro, relacionados com as teorias de partida $\mathrm{e}$ as complementam. Essa produção pode ser definida como "a teoria específica do objeto pesquisado". Esta pode ter a forma de proposições nomotéticas - se a pesquisa suporta tal tipo de afirmações; ou, mais provavelmente, de inferências, modelizações, "generalizações para a teoria" (YIN, 2005), novas hipóteses de investigação, novas perguntas de horizonte etc.

0 acionamento é a própria produção de teoria ou de articulação de hipóteses finais no corpo de teorias que ofereceram apoio para 0 desenvolvimento da pesquisa.

Observamos, então, quatro níveis diferentes de relacionamento entre teoria e pesquisa - no primeiro, a escolha de grandes perspectivas, de quadros gerais de inscrição; no segundo, os conhecimentos já estabelecidos que devem ser importantes para dar forma ao objeto; no terceiro, as teorias tensionadoras do objeto e tensionadas pelas questões "em elaboração" - ao mesmo tempo fornecendo bases para interrogar o objeto (e não para explicá-lo); no quarto, redirecionamentos, revisões e complementos aportados à teoria estabelecida pelos resultados da pesquisa, conforme as possibilidades do objeto e das descobertas realizadas.

Como é evidente, não são as teorias, per se, que se dispõem a ser articuladas com a pesquisa em uma ou outra posição. Tudo depende de nosso objeto, da problematização relacionada, dos objetivos da pesquisa e do que foi assumido como eixo. Somos levados assim fazer distinções entre diferentes possibilidades do acionamento teórico e a tomar decisões sobre o que faremos cada aporte teórico fazer em nossa pesquisa.

\section{A investigação propriamente dita - o trabalho de observação}

0 trabalho de observação sistematizada corresponde à investigação propriamente dita, à defrontação com a realidade, em que o pesquisador, munido de sua problematização e de suas bases teóricas, vai procurar elucidar suas questões através de um exame pertinente das coisas e situações.

Mas não basta, para "ir a campo", contar com um bom problema e teorias adequadas. É relevante ainda desenvolver um bom planejamento e organização do processo de abordagem dos 
materiais e/ou situações a serem investigadas.

Que conjunto específico de coisas, documentos, processos, situações e/ou pessoas deve ser observado? Tal decisão deve ser cuidadosamente elaborada, com previsão do que vai ser examinado, em que quantidades, variedade e especificidade. Que critérios e características agregam e dão consistência ao observável? Além desses critérios e características, que outras decisões devem ser tomadas, quanto a dimensão, locais, acesso, seleções, para a construção do conjunto a ser observado?

Essa construção, naturalmente, deve ser estabelecida em função do problema - prometendo viabilizar as elucidações que este busca. Deve ser também coerente com as premissas e com os fundamentos teóricos assumidos.

Como se caracteriza o material, em função das observações pretendidas? É relevante decidir se o mais promissor para nossas dúvidas é o exame acurado de um caso singular, se precisamos da representatividade de uma "população" (cuja amostra receberá, nesse caso, tratamento estatístico), se queremos observar uma diversidade de objetos pertencentes a uma mesma classe, se uma comparação entre duas situações promete desprender as informações requeridas para a descoberta.

Além da pertinência do observável, é claro que sua constituição deve levar em conta 0 tempo disponível pelo estudante. Uma previsão excessiva de materiais, ou uma diversidade de situações, que não conseguirão ser examinadas com a acuidade requerida na duração do mestrado ou do doutorado, leva ao risco de uma observação superficial e impressionística; ou, pior ainda, a uma amputação improvisada de parte das observações previstas, quando o momento imperativo da conclusão cai repentinamente sobre o pesquisador.

Outra questão relevante corresponde ao que deve ser observado no observável. 0s materiais e situações que interessam a uma pesquisa em Comunicação são geralmente complexos e abrangentes. Quando não trabalhamos com poucas variáveis, extraídas de seu contexto e controladas, nos defrontamos com uma grande diversidade interna do objeto; e com relações contextuais múltiplas - e esse é geralmente o caso, nos estudos qualitativos. É claro que a problematização elaborada, os objetivos da pesquisa, as hipóteses norteadoras, servem de critério para as decisões sobre os ângulos preferenciais dos objetos e sobre os contextos pertinentes - é relevante refletir sobre essas articulações.

Mas, além disso, devemos pensar sobre as "perguntas" que faremos ao objeto. Estas dependem das perguntas de pesquisa, mas não se confundem com elas. Como ilustração dessa 
distinção, podemos assinalar o equívoco que seria, em uma pesquisa sobre recepção, por exemplo, levar aos entrevistados, diretamente, nossas perguntas de pesquisa. 0 que obteríamos aí não seriam indicações sobre como as pessoas veem e interpretam tais e tais produtos midiáticos - e sim uma opinião a respeito dos ângulos hipotéticos que constituem nossa formulação. Se vamos observar documentos, não vamos "forçá-los" superficialmente na forma de nossas perguntas - devemos buscar sua lógica própria, tipicamente implícita, para então perceber as relações que vão dessa lógica às nossas perguntas de pesquisa.

A observação material da situação procura as pistas, busca constituir "dados" - elementos factuais que nos ofereçam informações básicas a serem interpretadas para atender às perguntas da problematização. "Perguntar ao objeto", decidir como organizar e sistematizar a observação corresponde a decidir que fatos, pistas, indicadores, dados, queremos fazer sobressair, com a expectativa de que estes respondam às perguntas da pesquisa.

Definidos esses "objetivos de levantamento de dados", é importante prever o acesso ao segmento de realidade pretendido - em dois aspectos: 0 acesso prático (obter contato com as coisas e/ou pessoas); e 0 acesso informacional (obter/extrair, do conjunto a ser observado, as informações específicas que interessam à pesquisa).

Correlato a esse processo - que leva ao trabalho sistemático da observação - é relevante pensar antecipadamente na forma de coleta, sistematização e formulação dos dados (informações, pistas etc.), de modo a ser possível, em continuidade, trabalhar interpretativamente sobre estes.

Diferente de uma reportagem, não vamos ao objeto apenas para alinhar e descrever fatos "que apareçam", objetivamente. É preciso ainda, sobre a observação - cujo modo adotado já deve ser uma decisão pertinente - relacionar, interpretar, inferir. Tal trabalho não pode ser nem improvisado nem impressionístico: decorre diretamente das provisões estabelecidas no problema e nos fundamentos. Assim, o planejamento sobre a coleta, a sistematização e a formulação dos dados, deve ser previsto para viabilizar e favorecer 0 trabalho interpretativo.

Um equívoco que às vezes ocorre é o de um levantamento muito abrangente e diversificado de dados mal sistematizados - sobre os quais não se sabe, depois, como trabalhar interpretativamente ou como gerar ordem no caos informativo, para poder desenvolver inferências.

Um último e importante ângulo sobre a questão é 0 trabalho de pré-observação.

Uma das dificuldades do planejamento - não só o plano de observação, mas todo o desenho da pesquisa, com seu problema e sua fundamentação teórica - é um eventual distanciamento da realidade das coisas. No nível da reflexão prévia, é relativamente fácil harmonizar todos os ângulos 
e gerar um projeto de pesquisa bem torneado.

Mas não é infrequente, quando se "vai a campo" para o trabalho prático da investigação, descobrir aspectos não previstos, que interferem em nosso planejamento. Não se trata apenas das dificuldades práticas: constatamos que a realidade é renitente e não se comporta como prevíamos. Se formos diretamente para 0 trabalho de investigação da realidade, com 0 projeto teoricamente estruturado, mas sem um contato prévio com a situação ou os materiais a serem investigados, podemos descobrir que algumas previsões não eram adequadas - em um momento no qual, diante de uma situação que "não obedece" ao desenho da pesquisa, já não se possam mais fazer as correções exigidas.

Um dos passos iniciais da pesquisa, por isso mesmo, deve ser um trabalho de pré-observação que, mesmo sem seguir delineamentos muito rigorosos - o planejamento geral ainda não terá sido completado - faça o mestrando ou doutorando interagir com o espaço em que futuramente vai pesquisar. Isso inclui pressentir as resistências do real, a aspereza dos processos não domados pela teoria, a indefinição dos contextos e das ocorrências confusas.

Assim, a pré-observação não é um levantamento preliminar de dados - é um processo exploratório para perceber melhor as necessidades de abordagem, solicitações postas à teorização, desafios dirigidos ao trabalho de problematização. Particularmente, na questão que nos ocupa neste item, esse trabalho exploratório prévio parece ser uma condição básica para o planejamento de uma observação sistematizada, um bom desenho da abordagem metodológica do objeto em seus aspectos mais materiais.

Um bom relatório de pré-observação não fala apenas sobre 0 encontro do pesquisador com a realidade elabora, a partir desse encontro, as injunções que a situação dirige a quem pretenda elucidá-la.

$$
* * *
$$

Nesse ponto, as articulações entre "problema", "teoria" e "observações" podem ser estudadas como um teste do projeto.

A escolha dos observáveis e os protocolos para o que vai aí ser especificamente observado são coerentes com as teorias acionadas? São pertinentes para o problema da pesquisa, prometendo dados e indícios favorecedores da descoberta segundo as perguntas feitas?

As teorias acionadas dão suporte ao problema, servem à elaboração de perguntas específicas? Oferecem um horizonte adequado para a curiosidade expressa no problema? 0s objetos abstratos abrangidos pela teoria (classes de objetos, conceitos referentes ao mundo) acolhem adequadamente os observáveis específicos selecionados - sem, entretanto meramente categorizá-los em respostas apriorísticas? Evitam pré-explicar, sem resto, os observáveis? 
0 problema da pesquisa refere adequadamente a base teórica que lhe dá fundamento?

Trabalha questões de horizonte oferecidas pela fundamentação adotada? Articula bem tais questões com perguntas específicas, voltadas para seu objeto de investigação? Dirige aos observáveis um plano de esquadrinhamento que efetivamente diz respeito às perguntas que caracterizam 0 eixo da investigação?

São apenas exemplos de questões-teste para checar a boa articulação do projeto. Ao fazer perguntas desse tipo para checar as relações entre estes componentes centrais, torna-se fácil perceber a necessidade de reajustes homeostáticos em um ou outro aspecto da pesquisa.

\section{Alguns riscos de desvio}

Na conjugação desses três elementos - problema, teoria, observação - podem-se perceber algumas armadilhas habituais.

Com a convicção de que a simples percepção de um risco já é um bom caminho para enfrentá-lo, apresento a seguir uma listagem dos desvios que tenho encontrado com maior frequência. Como se perceberá, a maioria desses riscos pode ser relacionada às reflexões apresentadas sobre os três elementos principais na articulação de uma pesquisa.

Os modos de enfrentar os riscos serão muito variados, e dependem dos projetos específicos, com suas problematizações, observáveis e aparatos teórico-metodológicos. Através de sua própria reflexão metodológica, os pesquisadores podem fazer ajustes para superação.

a. "Substituição" de um verdadeiro problema de pesquisa pelo tratamento de um tema, às vezes com erudição, mas sem busca de respostas e conhecimento; dispersão de ângulos, ideias, falas sucessivas sobre o objeto, meramente agregadas por acumulação, em vez de estruturadas por uma "questão a resolver"

b. Tratamento de teorias como mera resenha dos autores, sem relacioná-los pertinentemente com um problema específico em pesquisa; ausência de percepção da diferença entre estudar teoria e utilizar teorias a serviço de uma pesquisa.

c. Ausência de tensão entre teoria e objeto empírico, seja porque a teoria é doutrinariamente usada para "explicar" a realidade, em vez de "perguntar", seja porque 0 dado empírico torna-se mera ilustração da proposição teórica já dada como "verdade" (e não tensiona a teoria). Nas duas alternativas há uma prevalência abstrata da teoria.

d. Como um desdobramento da ausência de tensionamento teórico sobre o objeto, pode ocorrer que 0 trabalho de observar 0 objeto empírico resulte em mero "descritivismo" ou "classificacionismo". Nesse caso, 0 objeto empírico é tratado impressionisticamente, sem referência a conceitos e teorias que 0 organizem e construam enquanto "objeto de pesquisa". Ao 
contrário do risco anterior, aparece aqui uma prevalência empiricista do objeto. Esse terceiro desvio tende a coexistir com aquele apresentado no item "b".

e. Exposição de um problema excessivamente amplo, abrangente, não relacionado a um enfoque específico que possa ser diretamente investigado. Se o problema é tratado apenas no nível abstrato, geral, arrisca direcionar a um ensaio, e não a uma investigação. Nesse caso, o material empírico abordado não é efetivamente investigado, mas apenas tratado tematicamente, como mera "referência empírica" de uma argumentação que se desenvolve no abstrato.

f. Elaboração argumentativa em defesa de insights e posições prévias, uso de premissas como se fossem hipóteses - em vez de efetiva busca de conhecimento - e resultando que 0 fim da pesquisa, como consequência, apenas reafirma 0 ponto de partida. 0 pesquisador passaria, então a alegar "confirmação" das hipóteses de partida, quando as teria apenas reiterado, tautologicamente. Devendo-se lembrar, ainda, que em pesquisa qualitativa dificilmente nosso objetivo seria o de "confirmar hipóteses".

g. Correlato ao anterior seria a simples defesa militante de um ponto de vista já estabelecido, de uma posição prévia adotada pelo pesquisador que, em vez de buscar uma ampliação de conhecimento sobre um objeto, trabalhe apenas para "provar" que seu ponto de vista sobre esse objeto "corresponde à verdade". A diferença do anterior seria apenas de que, lá, trata-se de uma hipótese defendida; e aqui, de uma "posição", de uma "política" a respeito da realidade social.

Observo que assinalar esse risco não corresponde a pretender que o pesquisador deva trabalhar sem pontos de vista sobre a sociedade, que 0 conduzem em sua investigação. A diferença é que, no trabalho adequado, usam-se os pontos de vista como guia para investigar o objeto e para descobrir características suas (que podem tanto confortar as posições como sugerir complementações e redirecionamentos). 0 equívoco seria 0 de só enxergar no objeto aquilo que confirma os pontos de vista de partida, levando a um processo não de descoberta, mas de argumentação para confirmar aquilo em que já se acreditava.

h. Apagamento de uma efetiva abordagem metodológica em pesquisa, apenas imitada pela adoção de um jargão teóricometodológico estabelecido - sem que essa alegação abstrata produza encaminhamentos práticos de investigação.

i. Concepção de "pesquisa" e de texto acadêmico como verbalização abstrata e pedante, acessível apenas a iniciados ou a companheiros de "credo teórico", em vez de busca de conhecimento compartilhável e dirigido a leitores que, embora certamente 
escolados, não são conhecedores da questão específica - e em função dos quais, justamente, como gesto de compartilhamento, se expõem os resultados de uma pesquisa.

j. Pesquisa desenvolvida fora de enfoque comunicacional, inteiramente absorvida por angulações teóricas, metodológicas ou temáticas que, embora pertinentes como aporte ou espaço de interface, terminam por desviar o estudo - levando a consequências diversas, como o desencontro com as possibilidades de interlocução oferecidas pelo Programa de Pós-Graduação, a ausência do rigor específico da área vizinha mimetizada, a não-contribuição para o desenvolvimento do campo de estudos em Comunicação.

Alguns desses riscos são mais frequentes, outros menos. Alguns se articulam em círculo vicioso, outros aparecem pontualmente. Normalmente, uma tese ou dissertação não se apresenta como totalmente tomada pela presença deste ou daquele desvio. Os debates de orientação, as apresentações preliminares e parciais de textos referentes à pesquisa em curso, do estudante, tendem a trazer à luz aspectos menos claros, que podem assim ser facilmente corrigidos.

Não pensamos essa "indicação de riscos" como se fosse um check-list para análise de uma dissertação ou tese prontas - não creio que tivesse grande utilidade para isso. Penso, diversamente, no próprio processo de produção. Na medida em que o estudante e seu orientador adotem uma atitude de cuidado com relação a pontos como estes, a probabilidade de que a pesquisa corra tais riscos torna-se certamente reduzida.

\section{Objeções}

No item sobre "metodologias", acima, assinalei os cotejos internos ao próprio trabalho de pesquisa que oferecem base para revisões contínuas das articulações entre componentes - possibilitando, assim, assegurar um aperfeiçoamento da investigação pela construção de coerência interna entre os diversos processos.

Outra linha de ação metodológica deve ser ativada, ao lado desta - a partir de um olhar externo. Trata-se da submissão do trabalho (por seus produtos, mas também ainda na fase "em processo") à objeção dos pares e docentes.

Uma das características essenciais do trabalho acadêmico é a de estar constantemente sujeito à crítica da comunidade de reflexão e investigação. Quando um trabalho científico é publicado, está sendo, com sua própria divulgação, submetido ao olhar perscrutador dos demais pesquisadores, que poderão não só examinar sua coerência interna, como também sua inserção no âmbito mais vasto da área de conhecimento em que se propõe inscrito. Pode aí ser cotejado com outras perspectivas, outras teorias, outros modos de aproximação - que assim apresentam suas interpretações, apropriações e críticas. Submetese igualmente à crítica do acionamento que faz do conhecimento estabelecido, ao exame sobre 
o uso adequado ou não das teorias acionadas.

Enfrenta a reflexão sobre a qualidade e os bons fundamentos dos resultados apresentados.

É nesse processo que o empreendimento científico se justifica e legitima: pelo enfrentamento constante de todo e qualquer argumento, demonstração ou exposição factual que possa contestá-lo. As proposições novas, as contribuições ao conhecimento, para serem acolhidas, devem sobreviver a esse exame rigoroso. Uma proposição aceita e acolhida permanece sempre diante do risco da falseabilidade, na ocorrência de novas perspectivas que a superem.

Em síntese: faz parte intrínseca do processo e dos resultados da pesquisa, assim como da produção teórica, estarmos abertos à objeção. Esse processo é também um aliado inestimável no próprio desenvolvimento da pesquisa, pois as objeções feitas, longe de terem um cunho destrutivo, são um estímulo permanente ao aperfeiçoamento. Certamente, todos os que trabalham no campo acadêmico assumem tais perspectivas como estruturais, para a produção de conhecimento. Mas é preciso também realizar concretamente essa percepção no dia a dia da pesquisa e da formação de pesquisadores.

Para isso mesmo, o campo da formação acadêmica inclui previsões para que 0 exercício da objeção se realize e seja produtivo. Uma dessas previsões é justamente a injunção aos mestrandos e doutorandos para publicarem - os periódicos de cada área são o lugar principal de exposição da produção ao olhar crítico.

Outro âmbito relevante são os congressos e seminários de cada disciplina ou campo de conhecimento. 0 objetivo de viabilizar a objeção é aí tanto melhor servido quando a apresentação de textos ultrapassa o nível de mera exposição e estes são submetidos ao crivo do debate. Uma pesquisa em andamento oferece a possibilidade de elaboração de artigos que expressam estágios parciais do trabalho em curso. A simples apresentação - e com maioria de razão, o debate sobre tais textos - viabiliza a percepção, pelo próprio pesquisador, desse olhar externo que pode solicitar reformulações e contribui para a qualidade da pesquisa.

No espaço da Compós, acredito que nossas pesquisas em geral têm sido beneficiadas direta e indiretamente pelos debates de que participamos. No trabalho de nossos mestrandos e doutorandos, é para obter tal tipo de enfrentamento que, crescentemente, estimulamos a submissão de trabalhos a seminários e congressos. Estes correspondem a uma ampliação necessária do âmbito de objeções para fora do circuito interno de cada PPG.

Mas dentro dos PPGs, também, as oportunidades de acolhimento do olhar externo ao trabalho devem ser intencionalmente elaboradas. É com essa preocupação que devemos organizar todos os espaços que permitam ao estudante expor 0 estado em que se encontra sua pesquisa - seja pela 
apresentação de textos parciais, seja pela exposição dos processos em que se encontra engajado.

Frequentemente os PPGs incluem em sua estrutura curricular atividades expressamente voltadas para tal oportunidade de enfrentamento - e isso é possível desde 0 início da formação, uma vez que os estudantes ingressam já com uma proposta de pesquisa. 0 projeto pode ser aperfeiçoado a partir de dúvidas e objeções dos professores e dos colegas, desde que lhe seja dada a oportunidade de se expor.

Ao lado de atividades expressamente desenhadas com esse fim, na estrutura curricular, diferentes disciplinas, em diferentes formatos, costumam abrir a possibilidade de apresentação, no todo ou em parte, de propostas e perspectivas dos estudantes sobre sua própria pesquisa. Nessas ocasiões, submetê-las ao esquadrinhamento da análise crítica é uma contribuição relevante para a qualidade do trabalho.

Os exames de qualificação e/ou defesas de projeto, que a maioria dos programas inclui como requisito de formação, têm igualmente esse objetivo de aquilatar o grau de avanço na competência dos estudantes pesquisadores para enfrentar objeções e para, depois, fazer um bom proveito das críticas e recomendações recebidas.

Nossa experiência no PPG em Comunicação da Unisinos tem demonstrado que o exame de qualificação, realizado relativamente cedo no decurso da formação, repercute muito favoravelmente no andamento subsequente da pesquisa, devido à incidência da arguição sobre 0 estado da investigação, na medida mesmo da qualidade das objeções apresentadas em um momento em que o trabalho, já mais ou menos desenvolvido, se defronta com um olhar "externo"; e quando tem ainda tempo disponível para reformulações significativas. É também um bom momento - com dramaticidade adequada - para que os estudantes aprendam a incluir 0 trabalho de objeção como parte integrante do processo de conhecimento.

Assim, ao lado da repercussão "imediata" das objeções sobre a qualidade da pesquisa em curso, interessa também (e talvez mais ainda, pois tratase aqui do processo de formação do pesquisador) a aprendizagem das competências do estudante para desenvolver 0 sentido das objeções que encontra; para saber triar aquelas que possam efetivamente contribuir para seu trabalho; para realizar teórico-reflexiva no objetivo de enfrentar aquelas que não o convençam, pois não basta recusá-las in limine.

Para além dessas aprendizagens, a serem desenvolvidas no processo prático de enfrentamento, o estudante deve sobretudo desenvolver sua capacidade para prever objeções. Isso decorrerá, naturalmente, da prática de encontrar objeções ao que elabora, de compreender os âmbitos de reflexão e modos de investigar nos quais o seu trabalho de pesquisa vai circular - em síntese, da capacidade de se inscrever no campo de estudos em Comunicação 
percebendo suas tendências e solicitações, assim como as possibilidades de contribuição específica para 0 desenvolvimento desse campo.

Prever objeções é então uma capacidade relevante para o pesquisador - que pode assim de antemão se organizar para aproveitar os aportes dessa previsão e para elaborar argumentos e investigação um passo adiante, em aperfeiçoamento prévio. É nesse espaço, creio, que se evidencia com maior clareza a lógica do processo de arguição de tese e dissertação. Nesse evento, o estudante deve demonstrar, diante de uma diversidade de "leituras" de sua obra de formação, certo grau de competência para enfrentar objeções - que serão tanto melhor trabalhadas quando, com bom domínio daquilo que ele próprio elaborou, pode prever os diálogos a que seus processos e resultados serão solicitados a participar.

Correlatamente, a melhor arguição não é a que se dispõe como avaliação escolar da qualidade do trabalho realizado, ou que opõe alternativas de investigação para o objeto; e sim a que busca dialogar criticamente com aquilo que foi efetivamente feito, percebendo as lógicas internas do trabalho, para aí encontrar objeções e comentários voltados para sua superação.

É a defesa da dissertação ou da tese que expressa o grau de prontidão em que 0 estudante deve se encontrar ao final da formação. Representa, também, por isso mesmo, o modelo que devemos ter no trabalho de orientação.
0 apoio a ser dado ao orientando, com o melhor sentido metodológico, seria este, de prepará-lo e a sua pesquisa, para as objeções que fazem parte estrutural do processo de conhecimento. Como em toda formação prática, aprende-se a fazer fazendo. A formação do pesquisador através da elaboração de uma pesquisa é o exemplo mesmo desse tipo de formação. Aprende-se, portanto, a trabalhar com objeções enfrentando-as. Um dos principais papéis do orientador, mais significativo que a indicação de teorias e de caminhos, é a de oferecer uma atenção constante e uma disposição permanente para, apreendendo o que o estudante está elaborando, oferecer objeções instigantes.

\section{Conclusão}

As proposições apresentadas acima decorrem de situações concretas, trabalhadas em sala de aula ou em relações de orientação. Nas condições de origem, portanto, estiveram associadas a alguma dificuldade concreta e específica, a alguma percepção de efetivas relações entre questões de investigação e problemas teórico-metodológicos, a dúvidas sobre encaminhamentos práticos e a justificativas para decisões a serem tomadas pelos estudantes.

No processo de sistematização para gerar alguma consistência e para manter uma dimensão aceitável de páginas, abstraímos as circunstâncias concretas. Com isso, as proposições ganham em generalidade - mas ampliam seu distanciamento das questões específicas que lhes davam substrato. 
Ao mesmo tempo, 0 endereçamento das proposições se modifica. Na origem, foram esparsamente elaboradas nas situações enfrentadas - gerando falas de sala de aula, pequenos textos repassados aos estudantes, anotações diversas e debates com orientandos sobre seus problemas de pesquisa, comentários no contexto de arguições em bancas.

No presente texto, além de reunidas de modo mais ou menos sistemático, são dirigidas aos colegas preocupados com 0 trabalho de investigação de seus estudantes - principalmente na pós-graduação em Comunicação, mas possivelmente também nos trabalhos de conclusão de cursos de graduação; e a pesquisadores em formação, no seu enfrentamento pessoal com os desafios diversos de suas pesquisas.

Posso contar, então, com a experiência do leitor na própria atividade de ensino e orientação de pesquisa, ou de investigações em curso. No caso de mestrandos e doutorandos, é o interesse específico de suas pesquisas que deve completar uma lógica de leitura. Tais experiências, de orientação ou de enfrentamento da pesquisa, é que lhes permitirá acrescentar substância material sobre 0 que aqui aparece em forma abstrata. 0 trabalho de concretização ajudará a recolocar a visada de processos práticos que deve estar associada a tais reflexões. 0 que deve completar esse texto é o processo de sua reinscrição na prática.
Ao lado dessa vantagem com que o texto conta em seu endereçamento - 0 de ser desenvolvido pelos próprios leitores - deve-se reconhecer que se põe também como sujeito a objeções. A experiência vivida dos leitores pode sugerir, em suas situações concretas e específicas, diferentes percepções, outros encaminhamentos. Pode sugerir ainda, à leitura, uma interpretação diversa e inferências variadas. Mas acredito, justamente, que esse tensionamento, entre o que proponho e o que caracteriza a experiência e as preferências do pesquisador, é que deve ser propriamente produtivo.

Minhas proposições podem, em um ponto ou outro, contrastar com perspectivas do leitor e com sua experiência diferenciada. Essa diversidade será produtiva tanto pela complementação mútua; como pelas objeções que sejam apresentadas a este texto. Caso os leitores, sob o estímulo desse tensionamento, queiram compartilhar suas objeções, seus comentários, assim como perspectivas complementares, agradeço o envio destas. Serão bem acolhidas, como parte de um debate relevante em nosso trabalho comum de desenvolvimento da pesquisa e da formação pósgraduada na área da Comunicação.

\section{Referências}

0 presente artigo não é uma reflexão desenvolvida a partir de material bibliográfico. Como expresso no texto, as proposições apresentadas decorrem sobretudo da experiência prática do autor no enfrentamento de questões que se põem em disciplinas de metodologia de pesquisa em 
comunicação; e na análise de projetos de pesquisa, tanto no ambiente de formação, em PPGs, como na interlocução com agências de fomento à pesquisa.

Por outro lado, somos certamente devedores, nas reflexões, de leituras que serviram para dar sentido àquela experiência e para evitar descaminhos. Incluímos assim, por reconhecimento de tal dívida, as indicações a seguir. Estas servem também como sugestão de leitura, em complemento às que os eventuais interessados já acionam em seu trabalho de pesquisadores.

\section{BECKER, Howard S. Métodos de pesquisa em}

Ciências Sociais. São Paulo: Hucitec, 1993.

BOURDIEU, Pierre; Chamboredon, Jean-Claude;

Passeron, Jean-Claude. A profissão de sociólogo:

preliminares epistemológicas. Petrópolis: Vozes, 2002.

BRAGA, José Luiz; Calazans, Maria Regina.

Comunicação e Educação: questões delicadas na interface. São Paulo, Hacker, 2001.

BRAGA, José Luiz; LoPEs, Maria Immacolata Vassallo de; Martino, Luiz Cláudio (Org.). Pesquisa empírica em Comunicação. São Paulo: Editora Paulus, 2010.

BRAGA, José Luiz. Para começar um projeto de pesquisa. Comunicação e Educação. São Paulo, v. X, série 3, p. 288-296, 2005.

COULON, Alain. Etnometodologia. Petrópolis: Vozes, 1995.

DAMATTA, Roberto. Relativizando: uma introdução à antropologia social. Rio de Janeiro: Rocco, 1987.
DENZIN, Norman; Lincoln, Yvonna (Org.).

Handbook of qualitative research. California, EUA: Sage Publications, 2000.

ECO, Umberto. Como se faz uma tese. São Paulo: Editora Perspectiva, 2007.

GINZBURG, Carlo. Sinais: raízes de um paradigma indiciário. Mitos, emblemas, sinais: morfologia e história. São Paulo: Companhia da Letras, 1989.

GOLDMANN, Lucien. 0 Conceito de Estrutura Significativa na História da Cultura. Dialética e Cultura. Rio de Janeiro: Paz e Terra, 1970.

LAVILLE, Christien; DionNe, Jean. A construção do saber. Porto Alegre: Artmed, 1999.

MARTINO, Luiz Cláudio. Interdisciplinaridade e objeto de estudo da comunicação. In: HoHLFELDT; Antonio, Martino, Luiz Cláudio; França, Vera Veiga (Org.). Teorias da Comunicação: conceitos, escolas e tendências. Petrópolis: Vozes, 2001.

PIAGET, Jean. A situação das ciências do homem no sistema das ciências. Lisboa: Bertrand, 1971. POPPER, Karl. All life is problem solving. London, Routledge, 1999.

. A vida é aprendizagem: epistemologia evolutiva e sociedade aberta. Lisboa: Edições 70, 2001.

LOPES, Maria Immacolata Vassalo de. Pesquisa em Comunicação. São Paulo: Loyola, 1990.

YIN, Robert K. Estudo de caso: planejamento e métodos. Porto Alegre: Artmed, 2005. 
The practice of research

in Communication: a methodological approach to decision-making

\section{Abstract:}

The text has in its core the practical question of how to provide, according to the current reality of the Graduate Studies in Communication, student support for the referral of appropriate methodological theses and dissertations. It assumes that empirical research is a formative process, which is essential for master's and doctoral students. Considering the ineffectiveness of the adoption of strict and a priori methodological rules and also the variety of theoretical angles and object types in Communication Studies, it proposes perspectives for basic and crossmethodological care, appropriate to the diversity of qualitative research. The absence of a priori rules makes the reflexive decision-making a central element of methodology. The article offers propositions on three elements of the research: research problems, theoretical foundations and empirical observation. It deals, finally, with the objections as a central process to the advancement of knowledge.

\section{Keywords:}

Communication Research - Methodologies -

Curriculum - Theoretical Foundation - Systematic Observation - Objections.

\section{La práctica de la investigación en comunicación: un enfoque metodológico para la toma de decisiones}

\section{Resumen:}

El texto tiene como eje la cuestión práctica de cómo proporcionar, en la realidad actual de los programas de post-grado de Comunicación, apoyo para el encauzamiento metodológico adecuado de tesis y disertaciones. Supone que la investigación empírica es un proceso formativo esencial para los estudiantes de maestría y doctorado. Considerando la ineficacia en la adopción de reglas metodológicas apriorísticas y rígidas y la gran variedad de ángulos teóricos y de tipos de objeto en el área, propone perspectivas básicas y transversales para cuidados metodológicos, adecuadas a la diversidad de investigaciones cualitativas. Observa que el abandono de las reglas apriorísticas torna la toma ponderada de decisiones en un elemento central de la conducción metodológica. El artículo ofrece reflexiones sobre tres elementos de la investigación: problematización, fundamentación teórica y observación empírica. Finalmente trata de las objeciones como proceso fundamental en el avance del conocimiento.

\section{Palabras clave:}

Investigaciones de la Comunicación - Metodología - Problematización.- Fundamentación Teórica Observación Sistemática - Objeciones. 


\section{Expediente}

A revista E-Compós é a publicação científica em formato eletrônico da Associação Nacional dos Programas de Pós-Graduação em Comunicação (Compós). Lançada em 2004, tem como principal finalidade difundir a produção acadêmica de pesquisadores da área de Comunicação, inseridos em instituições do Brasil e do exterior.

\section{E-COMPÓS I www.e-compos.org.br I E-ISSN 1808-2599}

Revista da Associação Nacional dos Programas de Pós-Graduação em Comunicação.

Brasília, v.14, n.1, jan/abr. 2011

A identificação das edições, a partir de 2008

passa a ser volume anual com três números.

\section{CONSELHO EDITORIAL}

Afonso Albuquerque, Universidade Federal Fluminense, Brasil Alberto Carlos Augusto Klein, Universidade Estadual de Londrina, Brasil Alex Fernando Teixeira Primo, Universidade Federal do Rio Grande do Sul, Brasil Ana Carolina Damboriarena Escosteguy, Pontifícia Universidade Católica do Rio Grande do Sul, Brasil

Ana Gruszynski, Universidade Federal do Rio Grande do Sul, Brasil Ana Silvia Lopes Davi Médola, Universidade Estadual Paulista, Brasil André Luiz Martins Lemos, Universidade Federal da Bahia, Brasil Ângela Freire Prysthon, Universidade Federal de Pernambuco, Brasil Angela Cristina Salgueiro Marques, Faculdade Cásper Líbero (São Paulo), Brasil Antônio Fausto Neto, Universidade do Vale do Rio dos Sinos, Brasil Antonio Carlos Hohlfeldt, Pontifícia Universidade Católica do Rio Grande do Sul, Brasil Antonio Roberto Chiachiri Filho, Faculdade Cásper Líbero, Brasil Arlindo Ribeiro Machado, Universidade de São Paulo, Brasil Arthur Autran Franco de Sá Neto, Universidade Federal de São Carlos, Brasil Benjamim Picado, Universidade Federal Fluminense, Brasil César Geraldo Guimarães, Universidade Federal de Minas Gerais, Brasil Cristiane Freitas Gutfreind, Pontifícia Universidade Católica do Rio Grande do Sul, Brasil Denilson Lopes, Universidade Federal do Rio de Janeiro, Brasil Denize Correa Araujo, Universidade Tuiuti do Paraná, Brasil Edilson Cazeloto, Universidade Paulista, Brasil Eduardo Peñuela Cañizal, Universidade Paulista, Brasil Eduardo Vicente, Universidade de São Paulo, Brasi Eneus Trindade, Universidade de São Paulo, Brasil Erick Felinto de Oliveira, Universidade do Estado do Rio de Janeiro, Brasil Florence Dravet, Universidade Católica de Brasília, Brasil Francisco Eduardo Menezes Martins, Universidade Tuiuti do Paraná, Brasil Gelson Santana, Universidade Anhembi/Morumbi, Brasil Gilson Vieira Monteiro, Universidade Federal do Amazonas, Brasil Gislene da Silva, Universidade Federal de Santa Catarina, Brasi Guillermo Orozco Gómez, Universidad de Guadalajara Gustavo Daudt Fischer, Universidade do Vale do Rio dos Sinos, Brasil Hector Ospina, Universidad de Manizales, Colômbia Herom Vargas, Universidade Municipal de São Caetano do Sul, Brasil leda Tucherman, Universidade Federal do Rio de Janeiro, Brasil Inês Vitorino, Universidade Federal do Ceará, Brasil Janice Caiafa, Universidade Federal do Rio de Janeiro, Brasil Jay David Bolter, Georgia Institute of Technology Jeder Silveira Janotti Junior, Universidade Federal de Pernambuco, Brasil João Freire Filho, Universidade Federal do Rio de Janeiro, Brasil
John DH Downing, University of Texas at Austin, Estados Unidos José Afonso da Silva Junior, Universidade Federal de Pernambuco, Brasil José Carlos Rodrigues, Pontifícia Universidade Católica do Rio de Janeiro, Brasil José Luiz Aidar Prado, Pontifícia Universidade Católica de São Paulo, Brasil José Luiz Warren Jardim Gomes Braga, Universidade do Vale do Rio dos Sinos, Brasi Juremir Machado da Silva, Pontifícia Universidade Católica do Rio Grande do Sul, Brasil Laan Mendes Barros, Universidade Metodista de São Paulo, Brasil Lance Strate, Fordham University, USA, Estados Unidos Lorraine Leu, University of Bristol, Grã-Bretanha Lucia Leão, Pontifícia Universidade Católica de São Paulo, Brasil Luciana Panke, Universidade Federal do Paraná, Brasil Luiz Claudio Martino, Universidade de Brasília, Brasil Malena Segura Contrera, Universidade Paulista, Brasil Márcio de Vasconcellos Serelle, Pontifícia Universidade Católica de Minas Gerais, Brasi Maria Aparecida Baccega, Universidade de São Paulo e Escola Superior de Propaganda e Marketing, Brasil

Maria das Graças Pinto Coelho, Universidade Federal do Rio Grande do Norte, Brasil Maria Immacolata Vassallo de Lopes, Universidade de São Paulo, Brasil Maria Luiza Martins de Mendonça, Universidade Federal de Goiás, Brasil Mauro de Souza Ventura, Universidade Estadual Paulista, Brasil Mauro Pereira Porto, Tulane University, Estados Unidos Nilda Aparecida Jacks, Universidade Federal do Rio Grande do Sul, Brasil Paulo Roberto Gibaldi Vaz, Universidade Federal do Rio de Janeiro, Brasil Potiguara Mendes Silveira Jr, Universidade Federal de Juiz de Fora, Brasil Renato Cordeiro Gomes, Pontifícia Universidade Católica do Rio de Janeiro, Brasi Robert K Logan, University of Toronto, Canadá

Ronaldo George Helal, Universidade do Estado do Rio de Janeiro, Brasil Rosana de Lima Soares, Universidade de São Paulo, Brasil Rose Melo Rocha, Escola Superior de Propaganda e Marketing, Brasil Rossana Reguillo, Instituto de Estudos Superiores do Ocidente, Mexico Rousiley Celi Moreira Maia, Universidade Federal de Minas Gerais, Brasil Sebastião Carlos de Morais Squirra, Universidade Metodista de São Paulo, Brasil Sebastião Guilherme Albano da Costa, Universidade Federal do Rio Grande do Norte, Brasil

Simone Maria Andrade Pereira de Sá, Universidade Federal Fluminense, Brasil Tiago Quiroga Fausto Neto, Universidade de Brasília, Brasil Suzete Venturelli, Universidade de Brasilia, Brasil

Valério Cruz Brittos, Universidade do Vale do Rio dos Sinos, Brasil Valerio Fuenzalida Fernández, Puc-Chile, Chile Veneza Mayora Ronsini, Universidade Federal de Santa Maria, Brasil Vera Regina Veiga França, Universidade Federal de Minas Gerais, Brasil

\section{COMISSÃO EDITORIAL}

Adriana Braga I Pontifícia Universidade Católica do Rio de Janeiro, Brasil Felipe Costa Trotta I Universidade Federal de Pernambuco, Brasil CONSULTORES AD HOC

Édison Gastaldo I Universidade Federal Rural do Rio de Janeiro, Brasil Gisela Grangeiro da Silva Castro, Escola Superior de Propaganda e Marketing, Brasil Helio Kuramoto, Instituto Brasileiro de Informação em Ciência e Tecnologia, Brasil Juliano Maurício de Carvalho, Universidade Estadual Paulista, Brasil Maria Helena Weber, Universidade Federal do Rio Grande do Sul, Brasi Paulo Carneiro da Cunha Filho, Universidade Federal de Pernambuco, Brasil Vera Regina Veiga França, Universidade Federal de Minas Gerais, Brasil EDIÇÃO DE TEXTO E RESUMOS I Susane Barros SECRETÁRIA EXECUTIVA I Juliana Depiné EDITORAÇ̃̃o ELETRÔNICA I Roka Estúdio
COMPóS I www.compos.org.br

Associação Nacional dos Programas de Pós-Graduação em Comunicação

Presidente

Itania Maria Mota Gomes

Universidade Federal da Bahia, Brasil

itania@ufba.br

Vice-presidente

Julio Pinto

Pontifícia Universidade Católica de Minas Gerais, Brasil juliopinto@pucminas.br

Secretária-Geral

Ana Carolina Escosteguy

Pontifícia Universidade Católica do Rio Grande do Sul, Brasil carolad@pucrs.br 